\title{
Radiologic and functional outcome in patients with ipsilateral fractures of proximal femur and shaft treated by long proximal femoral nailing
}

\author{
Saju S. ${ }^{1 *}$, Thomas M. A. ${ }^{2}$ \\ ${ }^{1}$ Department of Orthopaedics, Government Medical College, Kottayam, Kerala, India \\ ${ }^{2}$ Department of Orthopaedics, Al Azhar Medical College, Thodupuzha, Kerala, India
}

Received: 04 October 2020

Accepted: 11 November 2020

*Correspondence:

Dr. Saju S.,

E-mail: drsajus@yahoo.com

Copyright: (c) the author(s), publisher and licensee Medip Academy. This is an open-access article distributed under the terms of the Creative Commons Attribution Non-Commercial License, which permits unrestricted non-commercial use, distribution, and reproduction in any medium, provided the original work is properly cited.

\begin{abstract}
Background: Combination of ipsilateral proximal femur and shaft of femur fractures are one of the rare fractures which were previously managed with two different implants for each fracture. Various studies have shown that long proximal femoral nailing is as effective as two different implants in fracture healing.

Methods: 25 cases in the age group of 20-80 years with ipsilateral proximal femur and shaft of femur fractures were enrolled from July 2014 to July 2017 and treated with long proximal femoral nailing. The cases were followed up at 6 weekly intervals and were assessed for their functional outcome using Friedman and Wyman criteria.

Results: Proximal femoral fractures united at an average time of $3.96 \pm 1.3$ months, whereas the mean time shaft of femur fractures took to unite was $5.67 \pm 3$ months. The mean time patients took to start full weight bearing was $6.15 \pm 2.76$ months. Functional assessment at 12 months revealed outcome as good in 18 (75\%), fair in $5(20.8 \%)$ and poor in 1 (4.1\%).

Conclusions: Long proximal femoral nailing is a good option in managing patients with ipsilateral proximal and shaft of femur fractures.
\end{abstract}

Keywords: Proximal femur and shaft of femur fractures, Long proximal femoral nailing, Functional assessment

\section{INTRODUCTION}

Combination of ipsilateral proximal femur and shaft of femur fractures are one of the rare fractures occurring in about $2.5-9 \%$ of femur fractures. ${ }^{1,2}$ But the incidence is on the rise because of the large number of road traffic accidents. Management of such fractures is a challenge to any orthopaedic surgeon as there are different surgical options described in literature like using single implant or two different implants for each fracture. Implants used vary from an antegrade intramedullary nail with cannulated cancellous screws, a dynamic compression plate (DCP) with a dynamic hip screw (DHS) or cannulated cancellous screws, a retrograde intramedullary nail with cancellous screws, and a reconstructive intramedullary interlocking nail. ${ }^{3-9}$ Advocates of two different implants argue that if there is failure of one implant or nonunion, there is need to revise that fracture fixation only. On the contrary those favoring single implant opine that this line of management reduces operating time and cost, with no need to open the fracture site, decreased blood loss and better cosmesis. ${ }^{10,11}$ Various studies have shown that long proximal femoral nailing is as effective as two different implants in fracture healing. ${ }^{12-}$ ${ }^{16}$ Hence an attempt is made to assess the same in our institution. In the last three years 25 cases with ipsilateral proximal femur and shaft of femur fractures were managed with long proximal femoral nailing. In this retrospective review we are trying to assess the time taken for each 
fracture to unite and the functional outcome 12 months after surgery.

\section{METHODS}

A retrospective study was conducted at Government Medical College, Kottayam on 25 patients who presented to the Accident and Emergency Department of the tertiary care centre. The study was approved at the Institutional Review Board and the Institutional Ethics Committee. A written informed consent was obtained from all patients who were selected for the study. The study was conducted by enrolling all patients with ipsilateral fractures of proximal femur and shaft of femur treated by long proximal femoral nailing between July 2014 to June 2017. All patients with arthritis hip and other joint diseases of hip, pathological fractures and other fractures or dislocation in the ipsilateral lower limb were excluded from the study. After getting approval for the study from institutional review board, patients who had undergone long proximal femoral nailing for ipsilateral fractures of shaft proximal femur were identified from operation register. The secondary data like date of injury, mode of injury, associated injury, date of surgery was collected from case sheet obtained from record library. Further the patients selected were intimated and were asked to attend Orthopaedics OP with all relevant records during which other details regarding their clinical profile which included date of full weight bearing, their radiological and functional outcome and complications if any were obtained. Information was collected through prepared proforma from each patient. All patients or their relatives were interviewed as per the prepared proforma and then complete clinical examination was done. Patient's follow up details at 6 weeks, 3 months, 6 months and 12 months were obtained from case records and $\mathrm{x}$ rays. The functional outcome was evaluated using Friedman and Wyman criteria. $^{17}$

\section{Surgical technique}

Patient was positioned on fracture table and traction was applied. Proximal femur fracture reduction was confirmed using $\mathrm{C}$ arm. If the fracture reduction was not satisfactory mini open techniques were used for reducing the same. Once the reduction is confirmed in anteroposterior and lateral images one or two $\mathrm{K}$ wires were passed anteriorly in the neck to keep the reduction in position in such a way that it does not obstruct the passage of nail which was proceeded with standard nailing technique for PFN. Shaft of femur reduction was obtained by closed method and nailing was completed. Proximal screws were put under $\mathrm{C}$ arm guidance using jig and distal locking bolts were put using freehand technique.

\section{After treatment}

Patients were followed up on a 6 weekly basis till fracture union was obtained at both sites clinically and radiologically. Functional assessment was done using Friedman and Wyman's criteria at 12 months.

\section{Statistical analysis}

Data was entered on a predesigned proforma for each individual patient. The data was then entered into an Excel work sheet and analysis was done using statistical package for social sciences (SPSS) version 16 (Trial version). Quantitative data was represented with mean and standard deviation whereas qualitative data was represented as percentages and proportions. Fixing the level of significance at 0.05 and level of high significance at 0.01 , statistical tests like and Chi square test or Fisher's exact test were used to assess statistical significance for categorical data.

\section{RESULTS}

Total cases enrolled for the study was 25 patients; of which one female elderly patient with co morbidities expired postoperatively. So final study analysis was done with 24 patients. All the patients who were finally obtained for follow up were males. The mean age of the cases was $42.71 \pm 10.5$ years.

Table 1: average time for union for proximal and shaft of femur fractures.

\begin{tabular}{|llll|}
\hline $\begin{array}{l}\text { Average } \\
\text { time for } \\
\text { union }\end{array}$ & $\begin{array}{l}\text { Neck of } \\
\text { femur }\end{array}$ & $\begin{array}{l}\text { Trochanteric } \\
\text { fracture }\end{array}$ & $\begin{array}{l}\text { Shaft of } \\
\text { femur } \\
\text { fracture }\end{array}$ \\
\hline $\begin{array}{l}\mathbf{2 - 3} \\
\text { months }\end{array}$ & $3(37.5 \%)$ & $10(62.5 \%)$ & $5(20.8 \%)$ \\
\hline $\begin{array}{l}\mathbf{4 - 5} \\
\text { months }\end{array}$ & $1(12.5 \%)$ & $4(25 \%)$ & $6(25 \%)$ \\
\hline $\begin{array}{l}>6 \\
\text { months }\end{array}$ & $4(50 \%)$ & $2(12.5 \%)$ & $\begin{array}{l}13 \\
(54.2 \%)\end{array}$ \\
\hline Total & 8 & 16 & 24 \\
\hline
\end{tabular}

The main mode of injury was road traffic accidents (68\%) followed by fall from height (32\%). Regarding the type of proximal femur fracture, $66.6 \%$ were trochanteric fractures and the rest $(33.3 \%)$ were neck of femur fractures. Mean Injury to surgery interval was 9.75 days (range 3-17 days). Post operatively, the average time taken for proximal fracture union was $3.96 \pm 1.3$ months whereas the average time taken for union of shaft of femur fracture was $5.67 \pm 3$ months, details of which is given in table 1 . The average time for union of neck of femur fracture was $4.5 \pm 1.6$ months whereas it took an average of only $3.6 \pm 1.1$ months for union of trochanteric fractures.

Radiological outcomes of selected cases are shown in figure 1,2 and 3.

Shaft of femur fracture union occurred earlier in younger age group (Fishers exact test, $\mathrm{p}<0.001$ ), but no relation was 
seen with age and proximal femur fracture union ( Fishers exact test, $\mathrm{p}=0.607)$. The age wise comparison of average time of union of proximal femur and shaft of femur is shown on table 2 .

Table 2: Average time of fracture union with respect to age categories.

\begin{tabular}{|lllll|}
$\begin{array}{l}\text { Age group } \\
\text { (years) }\end{array}$ & $\begin{array}{l}\text { Average time of } \\
\text { union proximal } \\
\text { femur }\end{array}$ & $\begin{array}{l}\text { Average time of } \\
\text { union shaft of } \\
\text { femur }\end{array}$ \\
\hline Mean & SD & Mean & SD \\
\hline $\mathbf{2 0 - 4 0}$ & 4.0 & 1.4 & 4.2 & 1.1 \\
\hline $\mathbf{4 1 - 6 0}$ & 4.2 & 1.12 & 6.8 & 3.5 \\
\hline
\end{tabular}

The mean time patients took to start full weight bearing was $6.15 \pm 2.76$ months. Functional outcome as assessed by Friedman and Wyman's criteria showed 75\% (n=18) with a good outcome, $20.8 \%(n=5)$ fair outcome and $4.1 \%(n=1)$ with a poor outcome.

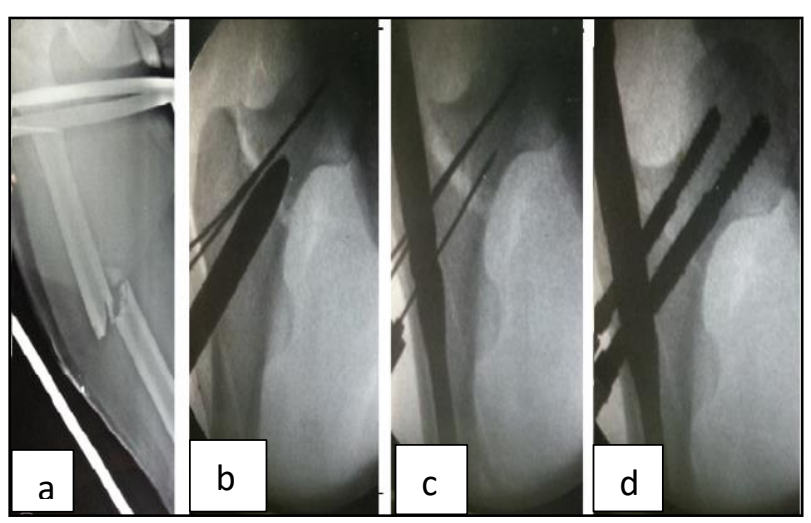

Figure 1: (a) Ipsilateral fractures of neck and shaft of femur, (b) Anterior $K$ wire for keeping the neck reduction in position, (c) Guidewire passage after nail insertion, (d) After insertion of both the head screws.

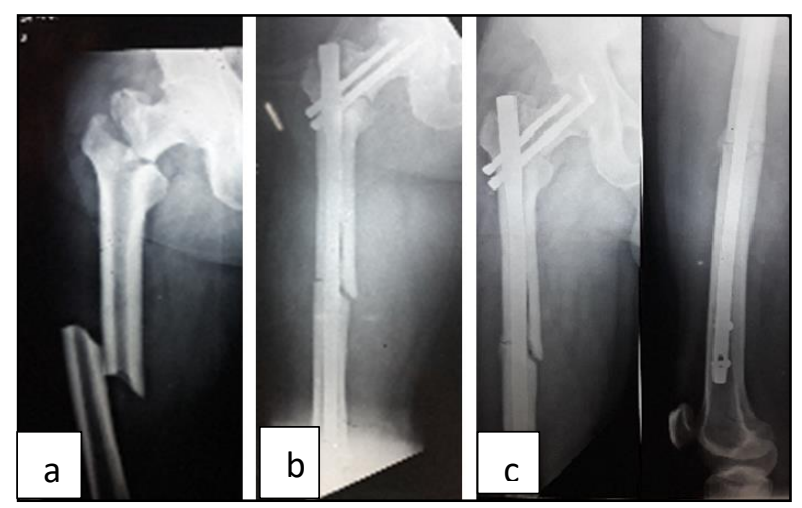

Figure 2: (a) Ipsilateral fractures of neck and shaft of femur, (b) Immediate post-operative x ray, (c) 18 weeks post-operative $x$ ray.

One case of non union shaft of femur was reported which was managed by bone grafting. There was another case with distal screw site infection which was managed with appropriate antibiotics. There were no cases of hardware failure and avascular necrosis of femoral head.

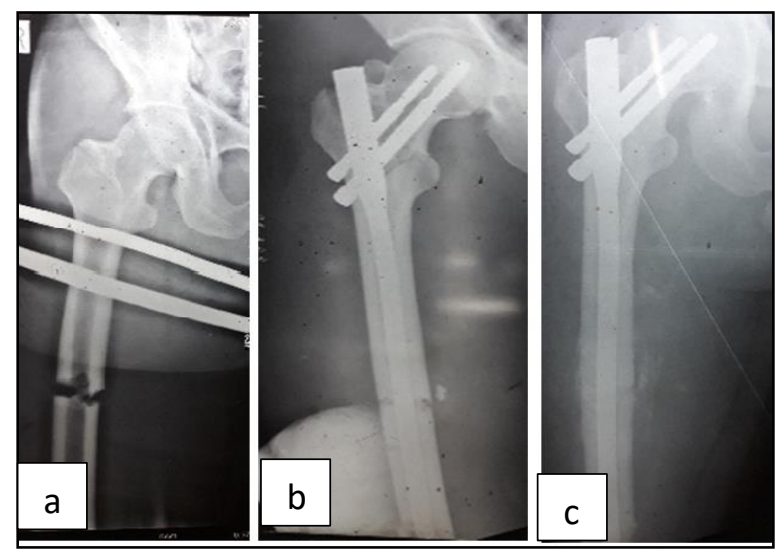

Figure 3: $X$ rays showing (a) Ipsilateral fracture of trochanter and segmental fractures of femur, (b) Immediate post-operative, (c) 18 weeks postoperative.

\section{DISCUSSION}

Ipsilateral fractures of proximal femur and shaft of femur are rare injuries which are difficult ones to manage. Different implants are used by surgeons to manage these types of fractures. There is no consensus regarding which one is the best. Studies conducted by Gary et al and by Singh et al in different settings showed comparable outcomes with double and single implants. ${ }^{18,19}$ In a study by Wiss et al, comparing antegrade Intramedullary (AI) nail and cancellous screw, retrograde intramedullary nail with cancellous screw and reconstruction nail, it was concluded that AI nail with supplemental screw fixation did not produce the desired outcome due to high rates of varus non-union of femoral neck fractures3. Further Alho et al conducted a meta-analysis, where 659 cases of concurrent, ipsilateral fractures in the hip and femoral shaft reported in 59 studies were analysed. ${ }^{20}$ According to that study locked intramedullary nails with separate hip screw and cephalomedullary nails yielded results which were superior to combinations of plates or unlocked nails and separate hip screws.

Studies by Gadegon et al and Dahuja et al conducted surgeries using proximal femoral nail for managing concomitant shaft and proximal femur fractures which produced reliable outcomes with minimal complications. ${ }^{14,16}$ Lee et al used reconstruction nail for managing these fractures with temporary $\mathrm{K}$ wire stabilisation of neck fractures. In this it was emphasized that neck fractures have to be reduced initially and fixed using temporary $\mathrm{K}$ wires before proceeding with reconstruction nail. ${ }^{13}$ This surgical stabilization technique avoids displacement of neck fractures and reduces the incidence of varus reduction.

The current study was done with proximal femoral nail among 24 patients with ipsilateral fractures of shaft and 
proximal femur. Such kinds of fractures are usually produced as a result of high velocity trauma which involves a force in the direction of femur proximally toward the neck of the femur as seen in dash board and motorcycle injuries. This can occur in fall from height also. In our study group $68 \%$ of the fractures were as a result of road traffic accidents and $32 \%$ were due to fall from height.

Patients enrolled were all males whose mean age was $42.71 \pm 10.5$ years being an older age group compared to other studies; with patients in such studies being in the mean age group of 36 years. (Mohapathra et al, Dahuja et al). ${ }^{16,21}$ There was a single incidence of missed neck of femur fracture which was later operated on. Such incidences of missed neck of femur fractures is quite common according to literature (19-31\%). ${ }^{22,23}$

As per this study, the mean injury to surgery interval was 9.75 days (range 3-17 days) which is acceptable as most of these fractures are associated with other system injuries. There was no association between injury surgery interval and time of union of fractures. According to Singh et al also there no relationship was established between injury surgery interval and final outcome of fracture union. ${ }^{19}$ The average time taken for proximal femur fracture union was $3.95 \pm 1.38$ months whereas the average time taken for union of shaft of femur fracture was $5.67 \pm 3$ months.). In a similar study of 36 patients, Gadegone et al observed the mean healing time for the neck fractures was 4.8 months and for the shaft fractures was 6.2 months. ${ }^{14}$

Functional outcome assessment by Friedman and Wyman's criteria showed that $75 \%$ of the patients had a good functional outcome at the end of 12 months. The results were comparable to a similar studies. ${ }^{12,14}$

\section{CONCLUSION}

Ipsilateral fractures of proximal femur and shaft have long been and still are a challenge to manage. The search for the ideal implant to treat such complex fractures is still going on; many studies stating a fairly good outcome, smaller incisions, less blood loss and minimal complications when compared to double implants .The results of the current study also points towards the evidence that long proximal femoral nail is a better option in managing patients with ipsilateral proximal femur and shaft fractures.

Funding: No funding sources

Conflict of interest: None declared

Ethical approval: The study was approved by the institutional ethics committee

\section{REFERENCES}

1. Wolinsky PR, Johnson KD. Ipsilateral femoral neck and shaft fractures. Clin Orthop Relat Res. 1995;318:81-90.
2. Watson JT, Moed BR. Ipsilateral femoral neck and shaft fractures: complications and their treatment.Clin Orthop Relat Res. 2002;399:78-86A.

3. Wiss DA, Sima W, Brien WW. Ipsilateral fractures of the femoral neck and shaft. J Orthop Trauma. 1992;6:159-66.

4. Wu CC, Shih CH. Ipsilateral femoral neck and shaft fractures. Retrospective study of 33 cases. Acta Orthop Scand. 1991;62:346-51.

5. Chen CH, Chen TB, Cheng YM, Chang JK, Lin SY, Hung SH. Ipsilateral fractures of the femoral neck and shaft. Injury. 2000;31:719-22.

6. Abalo, Dossim A, Ouro Bangnan AF. Dynamic hip screw and compression plate fixation of ipsilatéral femoral neck and shaft fractures. J Orthop Surg. 2008;16:35-38.

7. Swiontkowski MF, Hansen ST Jr, Kellam J. Ipsilateral fractures of the femoral neck and shaft. A treatment protocol. J Bone Joint Surg Am. 1984;66:260-8.

8. Alho A, Ekeland A, Grogaard B, Dokke JR. A locked hip screw-intramedullary nail (cephalomedullary nail) for the treatment of fractures of the proximal part of the femur combined with fractures of the femoral shaft. J Trauma. 1996;40:10-6.

9. $\mathrm{Wu} L D, \mathrm{Wu} \mathrm{QH}$, Yan SG, Pan ZJ. Treatment of ipsilateral hip and femoral shaft fractures with reconstructive intramedullary interlocking nail. Chin J Traumatol. 2004;7:7-12.

10. Jain P, Maini L, Mishra P, Upadhyay A, Agarwal A (2004) Cephalomedullary interlocked nail for ipsilateral hip and femoral shaft fractures. Injury. 35:1031-38.

11. Randelli P, Landi S, Fanton F, Hoover GK, Morandi M. Treatment of ipsilateral femoral neck and shaft fractures with the Russell-Taylor reconstructive nail. Orthopedics. 1999;22(7):673-6.

12. Pavleka T, Lihart M, Matejka J, Vyskocil V. Osteosynthesis of ipsilateral hip and femoral shaft fracture with a long PFN. Zentralbl Chir. 2005;130:148-52.

13. Lee SJ, Lee SH, Ha SH, Lee GC. Treatment for Concurrent Ipsilateral Femoral Neck and Shaft Fractures Using Reconstruction Nail with Temporary K-Wires. J Korean Fract Soc. 2015;28(1):23-29.

14. Gadegone W, Lokhande V, Salphale Y, Ramteke A. Long proximal femoral nail in ipsilateral fractures proximal femur and shaft of femur. Indian J Orthop. 2013;47(3):272-77.

15. Wu K, Lin S, Chou Y. Ipsilateral femoral neck and shaft fractures fixation with proximal femoral nail antirotation II (PFNA II): technical note and cases series. J Orthop Surg Res. 2020;15:20.

16. Dahuja A, Bhatty S, Bansal K, Kaur R, Shayam R. Role of PFN in ipsilateral fracture neck and shaft femur: a single solution to double fracture international Journal of Research in orhopaedics. 2018;4(3):384-88. 
17. Friedman RJ, Wyman ET. Ipsilateral hip and femoral shaft fractures. Clin Orthop Relat Res. 1986;208:188-194.

18. Gary JL, Taksali S, Reinert CM, Starr AJ. Ipsilateral femoral shaft and neck fractures: are cephalomedullary nails appropriate? J Surg Orthop Adv. 2011;20(2):122-25.

19. Singh R, Rohilla R, Magu NK, Siwach R, Kadian V, Sangwan SS. Ipsilateral femoral neck and shaft fractures: a retrospective analysis of two treatment methods. J Orthop Traumatol. 2008;9(3):141-47.

20. Alho A. Concurrent ipsilateral fractures of the hip and femoral shaft. A meta-analysis of 659 cases. Acta Orthop Scand.1996;67:19-28.
21. Mohapatra NC, Sethy GC, Rana R. Ipsilateral proximal femur and shaft of femur: A prospective analysis of two methods. J Orthop Traumatol Rehabil. 2017;9;17-20.

22. Alho A. Concomitant Ipsilateral fractures of the hip and femoral shaft of Femur. A systematic review of 722 cases. Ann Chir Gynaecol. 1997;86:326-36.

23. Bucholz RN, Rathjen K. Concomitant Ipsilateral fractures of the hip and femur treated with interlocking nails. Orthopaedics. 1985;8:1402-6.

Cite this article as: Saju S, Thomas MA.

Radiologic and functional outcome in patients with ipsilateral fractures of proximal femur and shaft treated by long proximal femoral nailing. Int J Res Orthop 2021;7:129-33. 